\title{
Laboreal
}

Volume $14 \mathrm{~N}^{\circ} 1$ | 2018

$\mathrm{O}$ regresso ao emprego após um acidente de trabalho

\section{O regresso ao trabalho após um acidente de trabalho : apresentação do dossier}

\section{Marianne Lacomblez e Augusto Rogério Leitão}

\section{Q OpenEdition}

Journals

Edição electrónica

URL: http://journals.openedition.org/laboreal/549

DOI: $10.4000 /$ laboreal.549

ISSN: 1646-5237

Editora

Universidade do Porto

Refêrencia eletrónica

Marianne Lacomblez e Augusto Rogério Leitão, «O regresso ao trabalho após um acidente de trabalho : apresentação do dossier », Laboreal [Online], Volume 14 NN$^{0} 1 \mid$ 2018, posto online no dia 01 julho 2018, consultado o 24 setembro 2020. URL : http://journals.openedition.org/laboreal/549 ; DOI : https://doi.org/10.4000/laboreal.549

Este documento foi criado de forma automática no dia 24 setembro 2020.

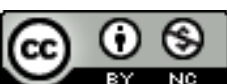

Laboreal está licenciado com uma Licença Creative Commons - Atribuição-NãoComercial 4.0 Internacional. 


\title{
O regresso ao trabalho após um acidente de trabalho : apresentação do dossier
}

\author{
Marianne Lacomblez e Augusto Rogério Leitão
}

\author{
NOTA DO EDITOR \\ http://dx.doi.org/10.15667/laborealxiv0118ml
}

\section{Um processo complexo e multifacetado}

1 Partindo do principio que 'regressar ao trabalho após um acidente de trabalho' se traduz na reintegração profissional do sinistrado em funções compatíveis com as limitações resultantes do desastre, várias questões levantam-se ainda sobre o modo como o empregador assegura tal regresso.

2 A legislação portuguesa desta matéria é, hoje, clara sobre esses aspetos. Nem sempre o foi. E para lá chegar o caminho se revelou, às vezes, sinuoso e tenso. Felizmente culminou, já nos inícios do século XXI, com a adoção de um novo quadro jurídicoinstitucional relativo a essa grave problemática social.

3 Assim, só a partir da Lei n.․ 98/2009, de 4 de setembro (que regulamenta o regime de reparação de acidentes de trabalho e de doenças profissionais, em vigor desde 1 de janeiro de 2010), foi estabelecido um regime jurídico relativo à reabilitação e reintegração profissional de trabalhador sinistrado com incapacidade temporária parcial, ou incapacidade permanente, parcial ou absoluta, para o trabalho habitual. E tal regime estipula, desde logo, que o empregador deverá assegurar a reabilitação profissional do trabalhador e a adaptação do posto de trabalho, bem como terá de ocupar o trabalhador que, ao seu serviço, ainda que a título de contrato a termo, sofreu acidente de trabalho ou contraiu doença profissional, em funções e condições de 
trabalho compatíveis com o respetivo estado (artigos $154^{\circ}$ a $166^{\circ}$ ). Na verdade, tais obrigações e ações de reabilitação e reintegração dos sinistrados estipuladas na lei, constituem novas prestações atribuídas no âmbito do sistema de reparação dos danos.

4 Mas convém não esquecer que a adaptação ao, e do, posto de trabalho referida convoca, na larga maioria dos casos, um contexto laboral que originou, essencialmente em razão de falhas técnico-organizacionais, o acidente registado. Tais falhas requerem, portanto, antes de tudo, análise e intervenção, porque sem um melhoramento das condições do desempenho da atividade, individual e coletiva, correr-se-á o risco de ver reiterado o processo anterior e a multiplicação de situações limites suscetíveis de provocar outros (novos) acidentes - sem menosprezar, no quadro do regresso do trabalhador acidentado, a probabilidade de se verificar uma acentuada deterioração da sua saúde, física e psíquica.

5 Nesta perspetiva, o regresso à atividade profissional insere-se na dinâmica de uma trajetória que tem início antes do afastamento forçado do local de trabalho e se prolonga num processo complexo, multifacetado, de reconhecimento do acidente, da avaliação dos danos provocados, da reparação desses mesmos danos e da reinserção profissional, em condições decentes, do sinistrado. Ora, não raras vezes, a configuração desta trajetória evidencia fatores de desigualdade, seja em função do nível de escolaridade, do setor de atividade, da situação laboral, da idade, ou do género. Tal como demonstram os artigos do dossier que apresentamos neste número da Laboreal, esse regresso ao trabalho pode, de facto, ocorrer em moldes muito diversos, conjugando, no pior dos casos, vários fatores de desigualdade, prejudicando particularmente os trabalhadores mais frágeis em termos de recursos profissionais e sociais.

6 O acidente de trabalho, ao impor deste modo uma dramática descontinuidade na vida profissional e, por extensão, nas demais dimensões da existência do trabalhador, pode originar uma profunda 'desestruturação das identidades' e mesmo 'provocar nos sinistrados sentimentos de perda e de desajustamento existencial comparáveis aos que decorrem da situação, também ela crítica, de desemprego', afetando ainda frequentemente 'a integridade física dos sinistrados e, consequentemente, a imagem que cada um constrói sobre o seu próprio corpo (...), bem como sobre a visão que os outros dele alegadamente formarão' (Pinto, 2017, p. 4 e 5).

7 Relembremos, ainda, que as ruturas decorrentes do acidente se tornam tão mais penosas, quanto mais longa for a ausência do sinistrado do seu quadro habitual de trabalho. Ora, as mais das vezes, a dilatação do tempo dessa ausência resulta das dificuldades encontradas no processo de reparação dos danos causados pelo sinistro, por via jurídico-administrativa. Com efeito, tal processo acaba, quase sempre, por envolver o sinistrado num desigual relacionamento com o direito e seus atores principais, que neste domínio são, fundamentalmente, os tribunais do trabalho e as seguradoras. E de facto, como realçou José Madureira Pinto, 'à familiaridade com o local de trabalho - nem sempre gratificante, mas previsível - sucede, abruptamente, a incerteza, vivida frequentemente como opressivo arbitrário institucional, de um labirinto de normas e procedimentos com o qual as vítimas têm de aprender a lidar (...)' (Pinto, 2017, p. 4 e 5). 


\section{Quatro artigos}

8 Eis, deste modo, apontado o objeto de estudo dos quatro artigos que compõem o dossier deste número da revista. Todos os textos exprimem a finalidade de identificar novas vias de intervenção, tendo em conta as múltiplas dificuldades encontradas pelos trabalhadores acidentados no percurso jurídico-institucional de reconhecimento do acidente, da reparação dos danos e da reintegração profissional.

9 Na verdade, estes artigos desenvolvem as suas análises no seguimento da participação de todos os autores numa mesma investigação, que foi solicitada pela Associação Nacional de Deficientes Sinistrados no Trabalho (ANDST), ativa em Portugal desde 1976. Não será, por isso, de estranhar uma relativa redundância quando os quatro textos referem as suas características metodológicas. A autonomia de cada artigo exigia, contudo, esclarecer a contextualização dos dados privilegiados nas respetivas análises já que, como o constatarão os leitores, cada uma tem a sua especificidade.

10 Assim, se o artigo de Vanessa Rodrigues descreve, logo no inicio, a problemática geral da pesquisa realizada para e com a ADNST, precisa, todavia, que a sua análise pretende sobretudo evidenciar, através de uma fundamentação teórico-empírica, elementos de compreensão sociológica do modo de organização e funcionamento da rede institucional que, em Portugal, materializa o quadro regulatório jurídico-social dos acidentes de trabalho. E, através de um levantamento cruzado e organizado de documentos jurídicos e administrativos, da doutrina jurídica, de dados de inquérito por questionário e de testemunhos recolhidos em entrevista e compilados em mapas de percurso, a autora procura sistematizar os principais momentos que constituem um percurso pós-sinistro. Concluindo que as práticas institucionais envolvendo tal percurso, especialmente as relativas à engrenagem da tramitação processual nos tribunais, e a experiência e perceção que sobre tais práticas têm as pessoas sinistradas, configuram um labirinto penoso, recheado de obstáculos e de impasses, para os trabalhadores acidentados e seus familiares.

11 A técnica dos mapas de percurso passou, de facto, a assumir um papel decisivo no avançar da reflexão coletiva. Claúdia Perreira e Vanessa Rodrigues consagram, portanto, um artigo às particularidades deste suporte metodológico. Lembram-nos que os métodos de reconstituição de percursos são largamente utilizados no âmbito das ciências sociais, com graus de complexificação e suportes teóricos diversificados. Porém, com um enfoque analítico direcionado a um percurso pós-sinistro, a abordagem que apresentam não se aproxima duma lógica puramente biográfica, sem relação com um contexto, aliás em constante transformação. Descrevem, então, como se conseguiu, deste modo, a reconstituição temporal de uma história que se inicia com um acidente, explorando o modo de relacionamento com as diferentes instituições responsáveis pela efetivação dos direitos resultantes de um acidente de trabalho, assim como com outros agentes sociais.

12 Todavia, como já referido, se defrontar com preocupações de um retorno ao trabalho exige ainda uma ancoragem da abordagem no real da atividade profissional em causa. Foi o que motivou Cláudia Pereira, Marta Santos e Liliana Cunha na sua exploração dos obstáculos com os quais os sinistrados do trabalho se deparam no regresso ao trabalho, sistematizando no seu artigo três grandes categorias de obstáculos: quando o regresso é feito à mesma função, mas sem uma análise e planeamento prévios; quando o conteúdo do trabalho atribuído não é objeto de debate com os trabalhadores; e quando o regresso 
é realizado sem ter em conta o facto de haver necessidade também de o coletivo de trabalho se reorganizar.

Este terceiro artigo argumenta igualmente, na sequência da reflexão de outros pesquisadores, sobre as potencialidades heurísticas de uma definição do acidente de trabalho como turning point no percurso profissional e pessoal. $\mathrm{O}$ artigo seguinte, de Bruno Monteiro e Virgílio Borges Pereira, prolonga de facto tal asserção, numa abordagem que se propôs recorrer à análise de correspondências múltiplas dos dados reunidos. Sustentam deste modo uma interpretação sociológica da experiência da dor e insistem na desigualdade associada à (re)produção de acidentes laborais, argumentando que as inscrições sociais dos trabalhadores e os dispositivos institucionais têm um contributo decisivo na configuração das experiências individuais de sofrimento póssinistro.

\section{Perspetivas e primeiro balanço do modelo jurídico- institucional português}

Este dossier pretende, antes de tudo, compensar a escassez dos estudos sobre o 'regresso ao trabalho após um acidente de trabalho', em Portugal e fora do país. Mas o seu objetivo, além de dar a conhecer investigações recentemente concluídas neste campo, é o de incentivar o desenvolvimento de novas linhas de pesquisa - que serão, e o os artigos aqui publicados demonstram-no, inevitavelmente pluridisciplinares. Pois, só assim se poderá caminhar no sentido de uma reflexão renovada acerca de todas as formas de apoio (individual, coletivo, institucional) suscetíveis de permitir ao.à trabalhador.a acidentado.a um regresso decente à vida ativa.

Na verdade, o cerne e os contornos destas problemáticas são fortemente determinados pelas configurações dos diferentes modelos jurídico-institucionais adotados pelos Estados, concernentes à reparação dos danos sofridos pelos trabalhadores acidentados, sobretudo no respeitante a indemnizações e pensões por incapacidades permanentes. Ora, sobre essa dimensão de política social, os Estados europeus não conhecem nenhuma harmonização das suas legislações e regulamentações, resultando as suas opções, acerca do modelo adotado, particularmente das dinâmicas da respetiva história social e política.

Certos países optaram por sistemas de responsabilidade social em que a responsabilidade de reparação está, regra geral, inserida na segurança social, isto é, assumida diretamente pelo Estado. Outros, como Portugal, elegeram um sistema de responsabilidade privada, em que a responsabilidade incide sobre a entidade empregadora que fica, contudo, obrigada a transferi-la para uma seguradora, que se tornará assim num ator muito importante do processo de reparação dos danos emergentes de acidentes de trabalho, tal como Vanessa Rodrigues sublinha no seu artigo.

17 Mas, de qualquer modo, o Estado (social) tem de assegurar que este modelo (privado) garante o interesse público subjacente à decisão da sua adoção/implementação, através, especialmente, de normas imperativas, de ações de fiscalização e de instrumentos públicos que assegurem subsidiariamente a reparação devida, missão essa que, no caso português, foi atribuída ao Fundo de Acidentes de Trabalho (FAT). 

acidentados vai centrar-se e depender, fundamentalmente, do (bom) desempenho do Tribunal do Trabalho, e, particularmente, das funções que a lei impõe e exige ao Ministério Público (MP), e, logo, do modo como tais funções serão exercidas pelos procuradores. Na realidade, o MP, no âmbito dos trâmites processuais, dirige a fase conciliatória, promovendo e fiscalizando um eventual acordo entre as partes envolvidas, ao serviço da legalidade e, pois, na qualidade de órgão de justiça. Só nos casos em que não se tenha alcançado consenso e o processo tenha que prosseguir para a fase contenciosa, o MP assumirá então o patrocínio do sinistrado e dos seus familiares, isto é, a defesa judiciária dos seus interesses e direitos. Mas tal não impede, que os sinistrados e seus familiares optem, igualmente, pelas demais alternativas que têm ao seu alcance: o patrocínio judiciário através de advogado constituído ou um patrono (advogado) nomeado ao abrigo do regime do apoio judiciário.

Por outro lado, o sistema português ao instituir o (seu) FAT, como organismo que subsidiariamente deverá garantir as prestações devidas aos sinistrados e seus familiares, nos casos de 'impossibilidade' de cumprimento da entidade empregadora ou/e da seguradora, limitou o campo da sua ação a certas situações tipificadas, ficando ainda tal ação fortemente dependente de decisões judiciárias e de despachos dos respetivos juízes.

Tal conceção normativa, da ação subsidiária a exercer pelo poder público, contribui para a formação de longos hiatos de tempo em que os interessados acabam por não usufruir de nenhuma proteção financeira. Além disso, o FAT português, contrariamente ao que se passa em instituições similares de outros países europeus, não exerce nenhuma função de apoio jurídico e de apoio social junto dos sinistrados e dos seus familiares.

21

Ora, estas particularidades, e outras que não são aqui apontadas, caracterizam o modelo português como muito pouco protetor, reforçando, assim, as assimetrias intrínsecas à relação salarial e as vulnerabilidades sociais, visíveis e invisíveis, a ela associadas, e, em especial, os processos de desestruturação vivenciados pelos trabalhadores em tais situações, tantas vezes dramáticas.

O sistema adotado pelo Estado português, relativamente à reparação no caso de acidentes de trabalho, parece-nos ser um dos mais frágeis e precário em vigor nos países da União Europeia. Daí que tenhamos já programado completar a análise desse assunto em próximos números da Laboreal.

\section{BIBLIOGRAFIA}

Pinto, J. (2017). Impactos do acidente sobre a vida profissional: rendimentos, emprego e relações de trabalho. Le Monde Diplomatique - Edição Portuguesa, n. 127, pp. 4-5 (Dossier O acidente de trabalho não é o fim da história). 


\section{AUTORES}

\section{MARIANNE LACOMBLEZ}

Centro de Psicologia da Universidade do Porto Faculdade de Psicologia e de Ciências da Educação Universidade do Porto Rua Dr. Manuel Pereira da Silva 4200-392 Porto, Portugal

lacomb@fpce.up.pt

\section{AUGUSTO ROGÉRIO LEITÃO}

Centro Observare, Universidade Autónoma de Lisboa Rua Santa Marta 56, 1169-023 Lisboa \& Faculdade de Economia, Universidade de Coimbra Av. Dr. Dias da Silva 165 3004-512 Coimbra, Portugal arleitao@fe.uc.pt arrcleitao@sapo.pt 